\title{
Reflexiones en torno al transporte y la inversión pública en ciudades intermedias. El caso de Arequipa, 2002- 2016
}

\section{Reflections on transport and public investment in intermediate cities. The case of Arequipa, 2002- 2016}

\author{
Alejandro Ochoa Arévalo (*) \\ Pontificia Universidad Católica del Perú \\ ORCID: 0000-0002-5731-6917
}

Fecha de recepción: 19 de enero

Fecha de aceptación: 14 de mayo

ISSN en línea: $2415-2498$

Ochoa Arévalo, A. (2018) «Reflexiones en torno al transporte y la inversión pública en ciudades intermedias. El caso de Arequipa, 2002-2016». Politai: Revista de Ciencia Política, Año 9, primer semestre, № 16: pp. 40-74.

DOI: https://doi.org/10.18800/politai.201801.002

\footnotetext{
* Tesista de pregrado de la facultad de Arquitectura y Urbanismo de la Pontificia Universidad Católica del Perú (PUCP). Es investigador en la sección Políticas Urbanas del grupo de investigación en Políticas Públicas y Gestión Pública (GIPPGP), del Observatorio de Políticas públicas para la Ciudad de la Escuela de Gobierno PUCP y del grupo de investigación de Urbanismo, Gobernanza y Vivienda Social (CONURB). Es activista y miembro fundador de la Unión de Estudiantes de Arquitectura de Lima (UDEAL). alejandroe.ochoa@pucp.pe
} 


\section{Sumilla}

El presente estudio propone, en la primera parte, la revisión descriptiva de los cuatro enfoques en el sector transporte y sus estrategias para generar soluciones presentes en la planificación de ciudades intermedias. Asimismo, se reconoce el proceso de cambio de las visiones y modelos de la ciudad de Arequipa contemporánea, a través del análisis cualitativo del enfoque del sector transporte de los dos planes directores ejecutados en los últimos 15 años con impacto importante para la relación.

El primer plan analizado (2002-2015) se orientó a la consolidación del área central, dos centralidades en el norte y sur, y cinco unidades funcionales articuladas por un sistema vial longitudinal de norte a sur, un anillo vial y una malla arterial complementaria. El segundo plan director (2016-2025) constituye la desconcentración del área central, la consolidación de dos centros secundarios (norte y sur), y seis centros terciarios articulados por corredores principales, secundarios y anillos de circunvalación. De tal manera, se marca una estructura urbana que considera articular centralidades y diversas aglomeraciones de viviendas dispersas en su expansión periférica.

En la segunda parte del estudio, se realiza la comparación cuantitativa y cualitativa entre los proyectos de inversión pública aprobados presupuestalmente por el Ministerio de Economía y Finanzas al gobierno provincial de Arequipa, y su vínculo con las propuestas elaboradas en los planes directores enunciados que sirven para la comprobación del nivel de ejecución real en la construcción de la ciudad.

El inicio a esta metodología que vincula la evaluación del enfoque en el sector transporte en los planes directores con la comprobación de la realización de proyectos de inversión pública constituye una herramienta en el proceso de fiscalización de las políticas urbanas ejecutadas por los gobiernos locales en ciudades intermedias.

Palabras clave: Transporte, inversión pública, ciudades intermedias, Arequipa, política urbana 


\begin{abstract}
The present study proposes, in the first part, the descriptive review of the four approaches in the transport sector and their strategies to generate solutions present in the planning of intermediate cities. Likewise, the process of changing the views and models of the city of Arequipa is recognized, through the qualitative analysis of the approach of the transport sector of the two master plans executed in the last 15 years with significant impact for the relationship.
\end{abstract}

The first plan analyzed (2002-2015) was oriented to the consolidation of the central area, two centralities in the north and south, and five functional units articulated by a longitudinal road system from north to south, a road ring and a complementary arterial mesh. The second master plan (2016-2025) constitutes the deconcentration of the central area, the consolidation of two secondary centers (north and south), and six tertiary centers articulated by main, secondary corridors and ring roads. In this way, an urban structure is marked that considers articulating centralities and diverse agglomerations of dispersed houses in their peripheral expansion.

In the second part of the study, a quantitative and qualitative comparison is made between the public investment projects approved budgeted by the Ministry of Economy and Finance to the provincial government of Arequipa, and its link with the proposals elaborated in the stated master plans that serve to checking the level of real execution in the construction of the city.

The beginning of this methodology that links the evaluation of the approach in the transport sector in the master plans with the verification of the realization of public investment projects constitutes a tool in the process of control of the urban policies executed by the local governments in intermediate cities.

Keywords: Transport, Public Investment, Intermediate Cities, Arequipa, Urban Policy 


\section{Introducción}

Desde años atrás, los cambios ocurridos en Arequipa reflejan la transición demográfica que afronta esta ciudad intermedia, que se caracteriza por la expansión urbana constante, la ubicación céntrica de los equipamientos urbanos dadores de servicios en la zona central y centro histórico.

En la zona central de la ciudad, la densidad se mantiene baja a media (Instituto Municipal de Planeamiento de Arequipa, 2016). Lo más claro es la provincia de Arequipa: principal centralidad histórica, funcional, administrativa de la ciudad intermedia, así en conjunto con los distritos adyacentes. Esta situación se mantiene, a pesar del inicio de importantes intervenciones inmobiliarias residenciales por toda la zona central. Al igual que en Lima metropolitana, «la densificación de las actividades urbanas se produjo debido a ciertas intervenciones urbanas públicas y privadas que se localizan en toda la ciudad, guiadas por el criterio capitalista de mercado» (Fernández de Cordova \& Vilela, 2015), desde el año 2002.

En este escenario, la implementación de políticas urbanas que promuevan la provisión de equipamientos e infraestructuras que otorguen servicios urbanos solo se ve en proceso de resolución en la zona central de la ciudad y un tanto ausentes en las zonas periféricas. Sin embargo, ciertas intervenciones de carácter comercial a escala barrial y distrital conllevan a la percepción de nuevas centralidades que atraen a la inversión inmobiliaria y, por ende, a la implementación de nuevas soluciones para la movilización de los pobladores de un punto a otro.

Este estudio, a partir del planteamiento marco de la relación entre instrumento de planificación e inversión pública, tiene como principal objetivo identificar, los cambios conceptuales del enfoque en el sector transporte presente en los planes directores (2002 y 2016) de la ciudad; y, cuanto ha sido la ejecución de gasto como indicador de sus implementaciones.

La aproximación metodológica, para visualizar la estructura vial de Arequipa, se basa en la revisión e identificación teórica de la visión de ciudad y las estrategias para la solución combatir la congestión y contaminación en las zonas urbanas en el sector de transporte, los cuales están presentes en los instrumentos de planificación. 
La visión de ciudad determina el modelo de ciudad al cual aspira el gobierno local, del cual se relaciona directamente al enfoque y estrategias para brindar soluciones en el sector de transporte.

Finalmente, se analiza comparativamente, con la información de trasparencia económica brindada por el Ministerio de Economía y Finanzas, los gastos realizados en proyectos de inversión pública en los años 2012, 2013, 2016 y 2017 de las gestiones del gobierno municipal provincial de Arequipa.

\section{Los enfoques de transporte y los planes directores: el caso de Arequipa.}

Esta parte está orientada a la descripción de los enfoques teóricos de transporte en zonas urbanas. Seguidamente, se identificará la visión y el modelo de ciudad para Arequipa que se encuentran especificados en los planes directores 2002 y 2016. Finalmente se esboza un breve análisis sobre el tipo de enfoque de transporte que abordan ambos planes.

\section{a. Los enfoques de transporte: del tráfico a la movilidad sostenible}

«Las políticas urbanas desarrolladas y adoptadas, por los gobiernos locales, regionales y estatal, en la lucha contra la congestión vial y contaminación a lo largo de los años han sido muy diversas» (Dextre y Avellaneda, 2014).

Dextre y Avellaneda determinan cuatro enfoques con una estrategia cada uno.

\begin{tabular}{|c|c|}
\hline Enfoque & Estrategia \\
\hline Tráfico & Aumento de la capacidad vial \\
\hline Transporte público & Prioridad al Transporte público \\
\hline Movilidad & $\begin{array}{c}\text { Brindar movilidad a todos los } \\
\text { usuarios }\end{array}$ \\
\hline Movilidad Sostenible & Movilidad y accesibilidad sostenible \\
\hline
\end{tabular}

Cuadro 1. Enfoques del sector transporte y estrategias. Elaboración propia en base a Dextre y Avellaneda (2014). 
El primer enfoque es el énfasis en el tráfico donde la estrategia principal es aumentar la capacidad vial o construir más infraestructura para autos privados y públicos: intercambios viales (tréboles), pasos a desnivel (bypass), pasos elevados, estacionamientos, ampliación de carriles, puentes, entre otras. En el caso de Arequipa, pueden resaltarse obras viales como la construcción de la vía troncal interconectora entre distritos de Miraflores, Alto Selva Alegre, Yanahuara, Cayma y Cerro Colorado en la provincia de Arequipa.

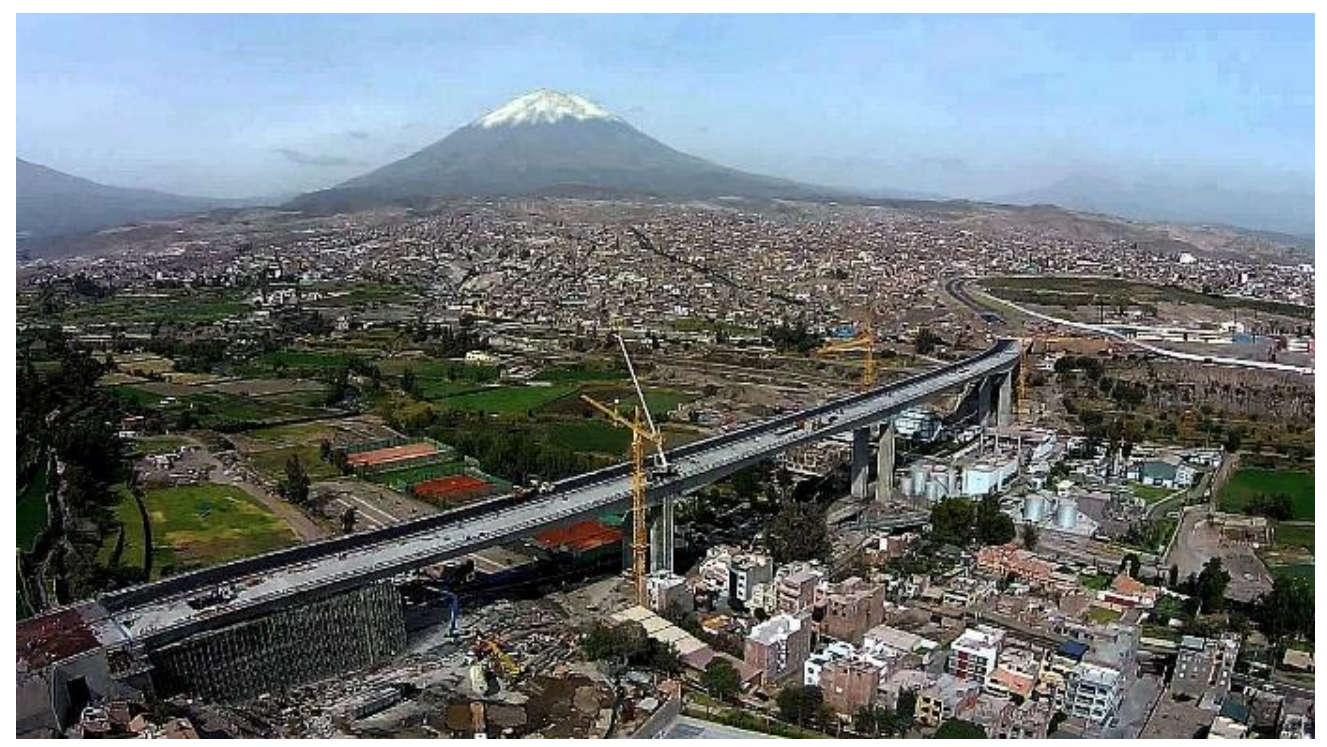

Imagen 1. Construcción de vía troncal interconectora entre distritos de la provincia de Arequipa. Fuente: http://elcomercio.pe/economia/peru/los10-proyectos-obras-impuestos-masgrandes-peru-noticia-1869841 


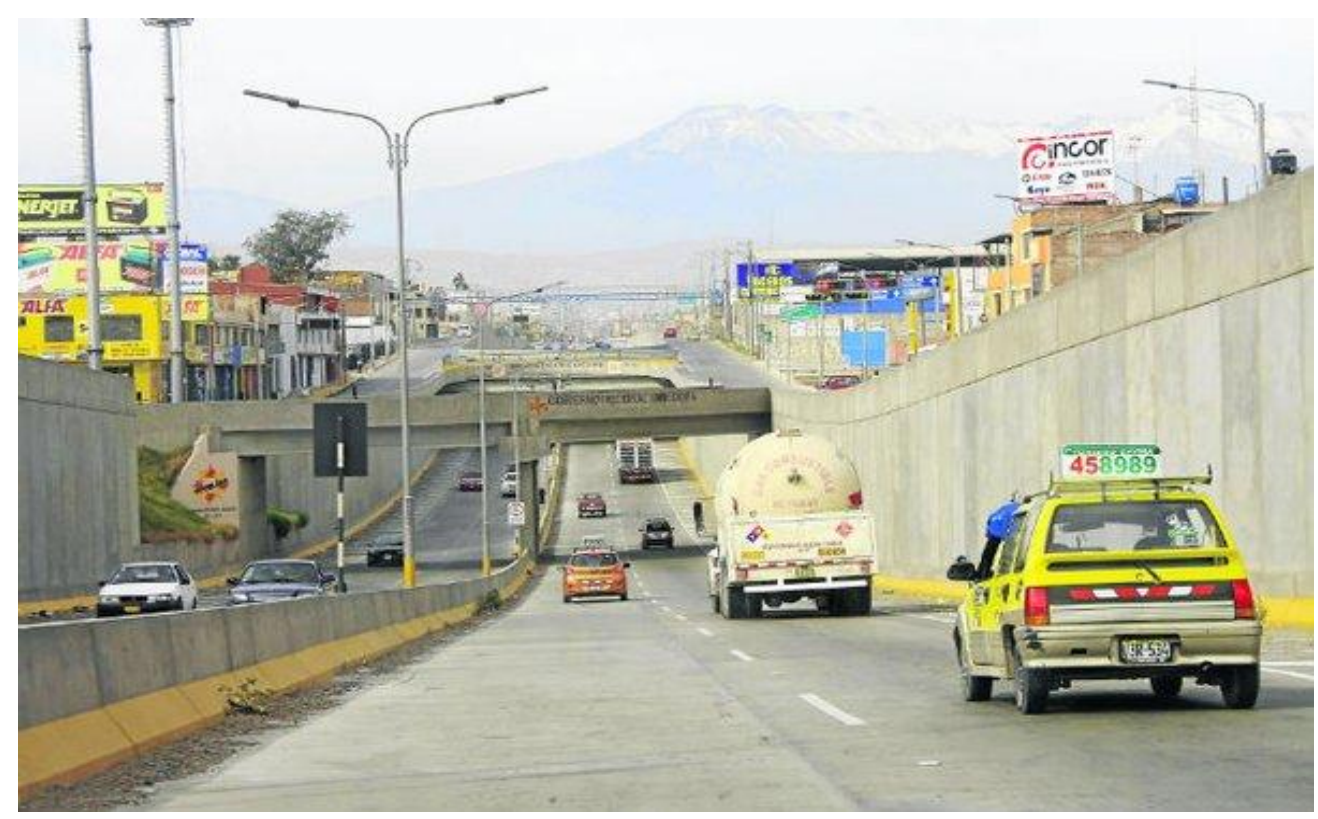

Imagen 2. Paso a desnivel en Uchumayo, Arequipa. Fuente: http://diariocorreo.pe/edicion/arequipa/sa-640073/

La propuesta de habilitar infraestructura vial puede traer consigo, a corto plazo, beneficio para miles de familias a través de la interconexión con otros distritos. Sin embargo, la imagen 1 también indica cómo la vía troncal deprecia la calidad de vida de las personas que residen cerca de la colosal infraestructura y afectando al paisaje natural colindante al margen derecho. La vía troncal se vuelve un borde en la ciudad y posiblemente sea un lugar que genere inseguridad y peligro. De igual manera, en la imagen 2 se observa cómo la prioridad en la construcción de la ciudad es para los autos, nuevamente el bypass genera una división en el territorio.

El modelo territorial detallado por Herce en el gráfico 1 que se genera a partir de la construcción de más infraestructura vial es disperso, donde se necesitan realizar mayores desplazamientos por día y son de mayor longitud. La dispersión urbana genera menor densidad en la ciudad, lo cual produce mayor dependencia del automóvil e incrementa, finalmente, el consumo energético y la exclusión social. Las consecuencias de un modelo de ciudad dispersa son lo que contrariamente se producen en un modelo territorial donde se ha 
desarrollado la compacidad. En 1964, en el informe «traffic in towns» (Buchanan, 1973) se detalla que el incremento de este tipo de infraestructura genera un círculo vicioso que se determina como «demanda inducida» ${ }^{1}$.

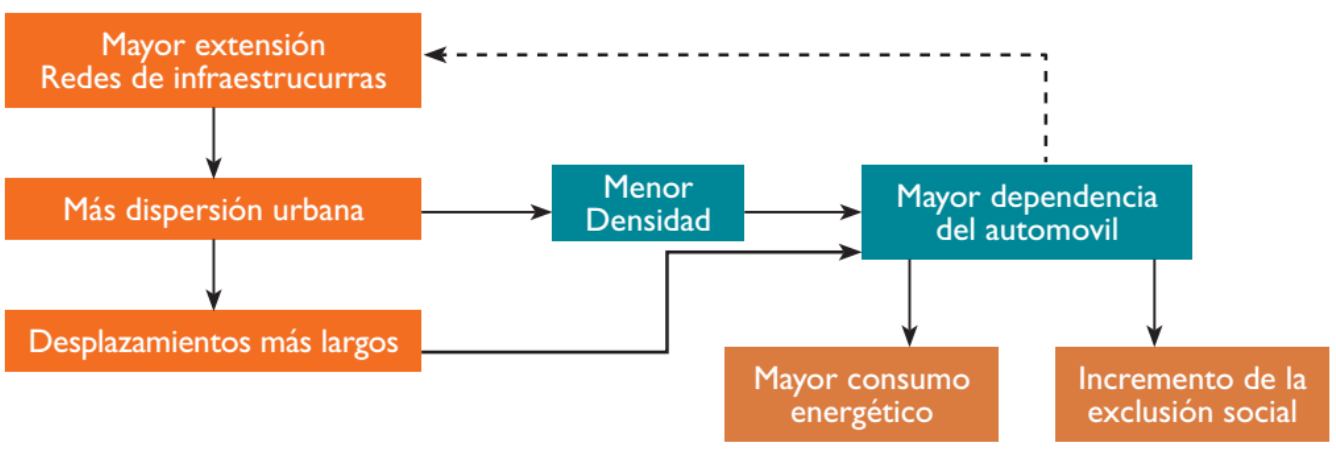

Gráfico 1. Modelo territorial que produce dispersión (no sostenible). Fuente: Herce, M. (2009). Sobre la movilidad en la ciudad. Propuestas para recuperar un derecho ciudadano.

El segundo enfoque es el énfasis en el transporte público donde la estrategia principal es promocionar uso del transporte público y aumentar la capacidad para trasladar pasajeros de un punto a otro. Esto se traduce en mejorar la eficiencia del transporte colectivo, lo que conlleva a beneficios como contaminar menos, aprovechar el espacio público, disminuir el índice de accidentes. Los dispositivos para la movilización de pasajeros pueden ser el metro, trenes, buses de transporte rápido (BTR), tranvías, monorrieles, entro otros. Con este modelo las personas se seguirán trasladando las mismas distancias, pero en menor tiempo.

\footnotetext{
${ }^{1}$ Entiéndase como la acción de organizar, incentivar u orientar a un determinado grupo social la utilización de un servicio o un producto, el cual no siempre es necesario.
} 


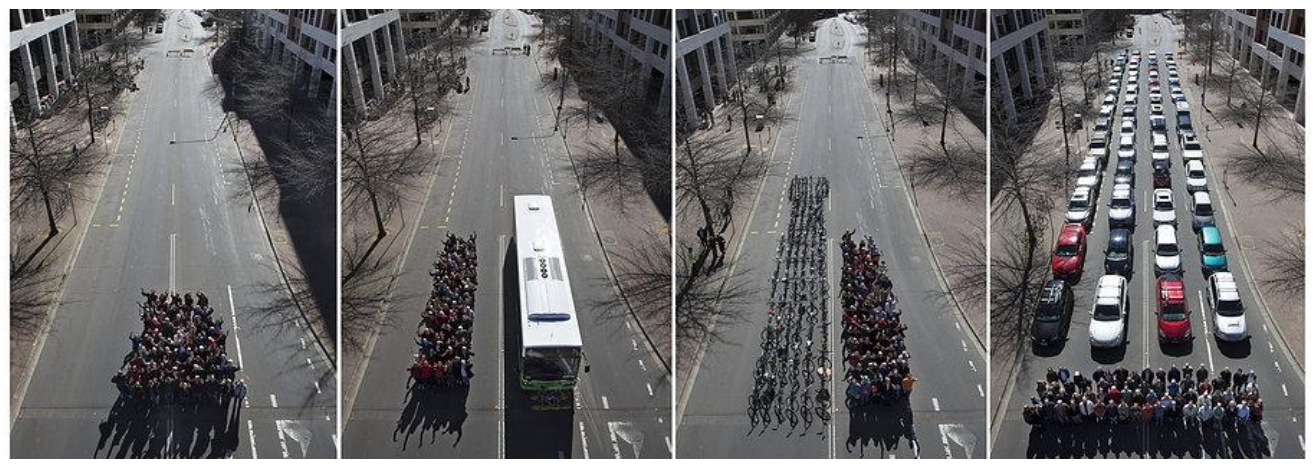

Imagen 3. La ocupación y eficiencia del espacio del transporte público versus el transporte privado. Fuente: https://www.cyclingpromotion.org/

No obstante, Dextre y Avellaneda consideran en su análisis que no es suficiente robustecer el transporte público, si no acortar las distancias de viaje. Reducir la distancia de viaje está directamente relacionado con la reformulación de un modelo de ciudad «disperso» a uno «compacto», el cual está ligado a los términos de movilidad y movilidad sostenible.

El tercer enfoque es el énfasis en la movilidad donde la estrategia principal es la identificación de la diversidad de usuarios y su movilización en el territorio (Sanz, 2008). En la diversidad se encuentra la clave para el diseño de la ciudad, el cual se nutre de varias disciplinas como el Urbanismo, la Geografía, la Psicología, la Ciencia Política, entre otras. Las diversidades de los usuarios van desde las cualidades y características del peatón (personas con discapacidad visual, motora, auditiva, cognitiva; niño; persona de tercera edad; adulto) hasta el uso de dispositivos no motorizados (patines, patín, bicicleta) y motorizados (moto, auto, bus, tren, metro). 


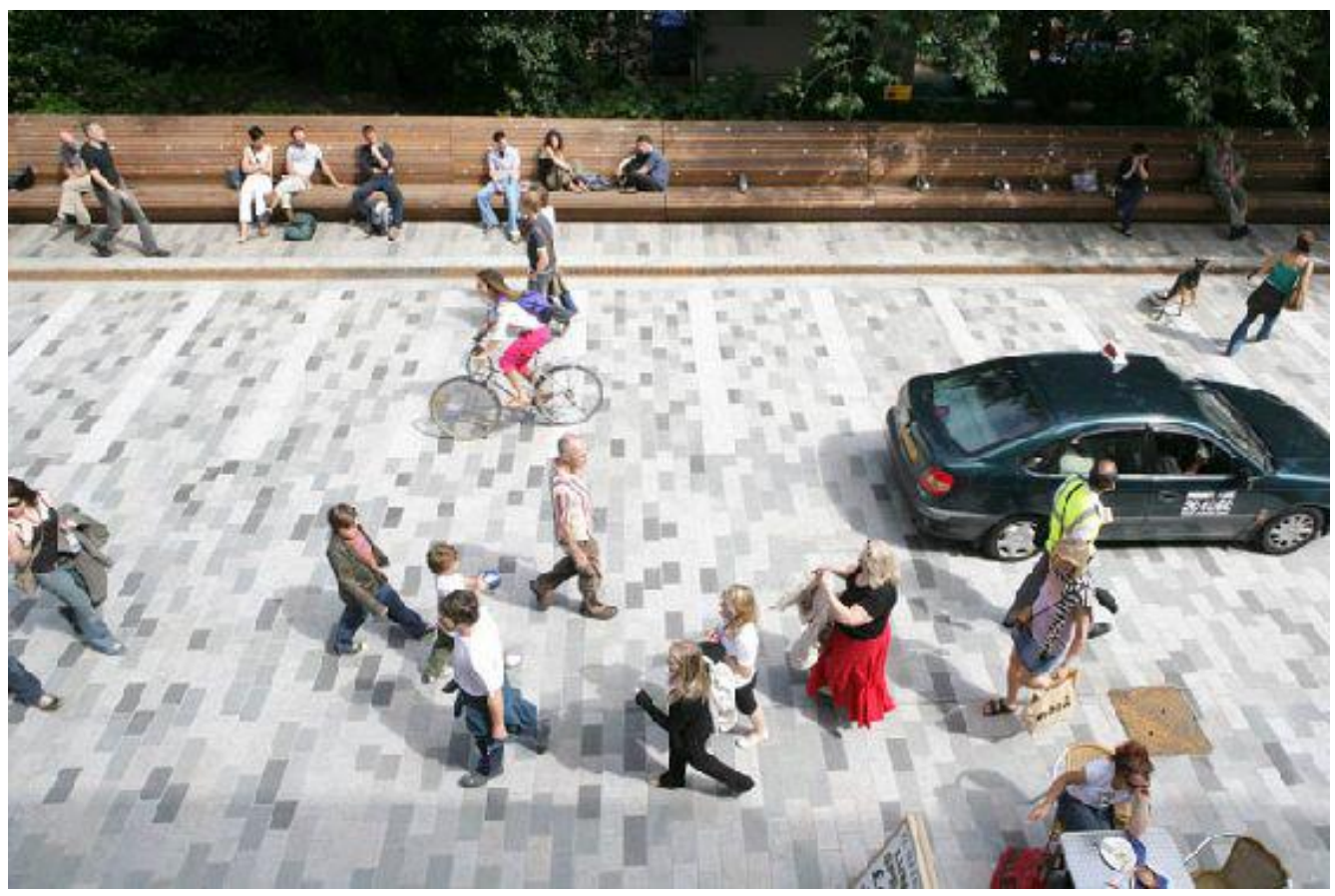

Imagen 4. Diversidad de usuarios y su interacción en el espacio abierto. Fuente: http://scielo.sld.cu/scielo.php?script=sci_arttext\&pid=S1815-58982012000100003

Además, investigaciones como las de Sanz, Cebollada (2007), Novas (2014) y Vega Centeno (2004) plantean el análisis de la movilidad a partir del enfoque de género, donde se reconoce que las mujeres tienen un patrón distinto al de los varones; Tonucci (2004) haciendo énfasis en los niños; o Tyler (2002), en personas con discapacidad. Por consiguiente, la ciudad se reconceptualiza en diseño para la movilización y sistema de transporte que responda a la necesidad de todos y todas.

El cuarto enfoque hace énfasis en la movilidad sostenible donde la estrategia principal es la relación directa entre desplazamiento y consecuencia ambiental. En esta etapa final, la importancia sobre el reordenamiento territorial es fundamental para la estructuración de la ciudad como la articulación de nuevos espacios urbanos con un carácter de centralidad multidimensional (Beuf, 2010) que pueden estar o no dentro de un marco de compacidad, concepto acuñado por Oliva (2005) y Rueda 
(2002). Adicionalmente a lo enunciado, Sanz (1997) determina dos conceptos importantes: movilidad sostenible y accesibilidad sostenible.

La movilidad sostenible hace referencia a combatir los problemas ocasionados por el tráfico, en una mayor escala, a partir de la «sustitución de transportes motorizados por otros de mayor eficacia ambiental y social» (Sanz, 1997). La relación es directa con lo mencionado en la segunda etapa sobre el robustecimiento del transporte masivo. La accesibilidad sostenible hace referencia a una escala menor y a la disminución de la movilidad motorizada siendo reemplazada por opciones como el desplazamiento peatonal o en bicicleta.

Las recomendaciones como estrategias para implementaciones en políticas urbanas citadas por Sanz:

\begin{tabular}{|c|c|}
\hline Tipo & Estrategias \\
\hline $\begin{array}{l}\text { Movilidad } \\
\text { Sostenible }\end{array}$ & $\begin{array}{l}\text { - Mejora y coordinación de las redes de transporte colectivo. } \\
\text { - } \\
\text { ciberación de espacio viario para su uso por los vehículos del transporte } \\
\text { - Mejora de las estaciones y terminales del transporte colectivo para } \\
\text { aumentar su atractivo. } \\
\text { - Mejora de la imagen pública del transporte colectivo y de sus cualidades } \\
\text { sociales y ambientales. } \\
\text { Reducción del consumo energético, de las emisiones contaminantes y del } \\
\text { ruido producido por los vehículos del transporte colectivo. }\end{array}$ \\
\hline $\begin{array}{c}\text { Accesibilidad } \\
\text { sostenible }\end{array}$ & $\begin{array}{l}\text { - } \quad \text { Promoción e incentivos para los desplazamientos andando y en bicicleta. } \\
\text { - } \quad \text { Creación de redes de itinerarios peatonales y ciclistas. } \\
\text { - } \quad \text { Supresión de barreras para peatones y ciclistas. } \\
\text { - } \quad \text { Rehabilitación cultural de los desplazamientos peatonales y ciclistas. }\end{array}$ \\
\hline
\end{tabular}

Cuadro 2. Estrategias para la movilidad y accesibilidad sostenible. Elaboración propia en base a Sanz (1997)

La compacidad, policentricidad (Sánchez, 2013) y diversidad (Rueda, 1997) son conceptos relacionados complementariamente a la movilidad y accesibilidad sostenible y que son parte de un modelo de ciudad ideal. 


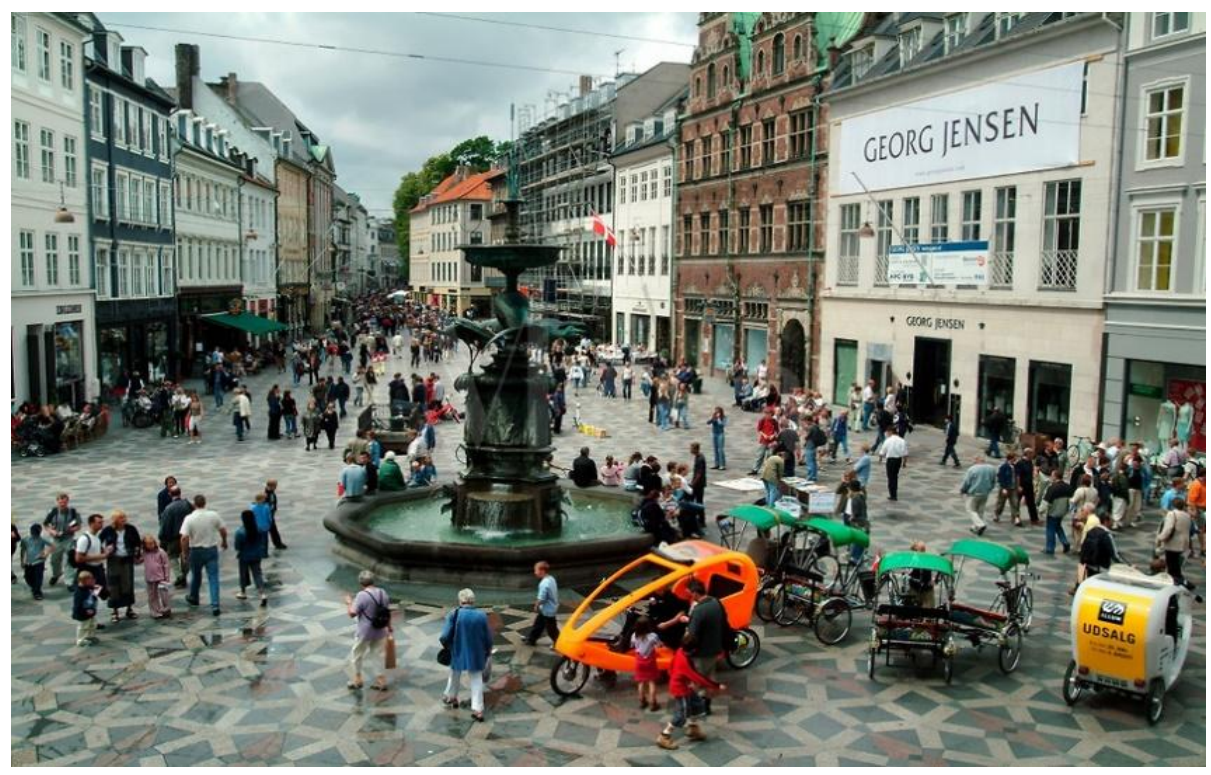

Imagen 5. Stroget, Copenhague. Calle peatonalizada en beneficio de los usuarios. Ejemplo notable de accesibilidad sostenible. Fuente: http://nrfuture.com/idea/strogetcopenhagen-denmark/

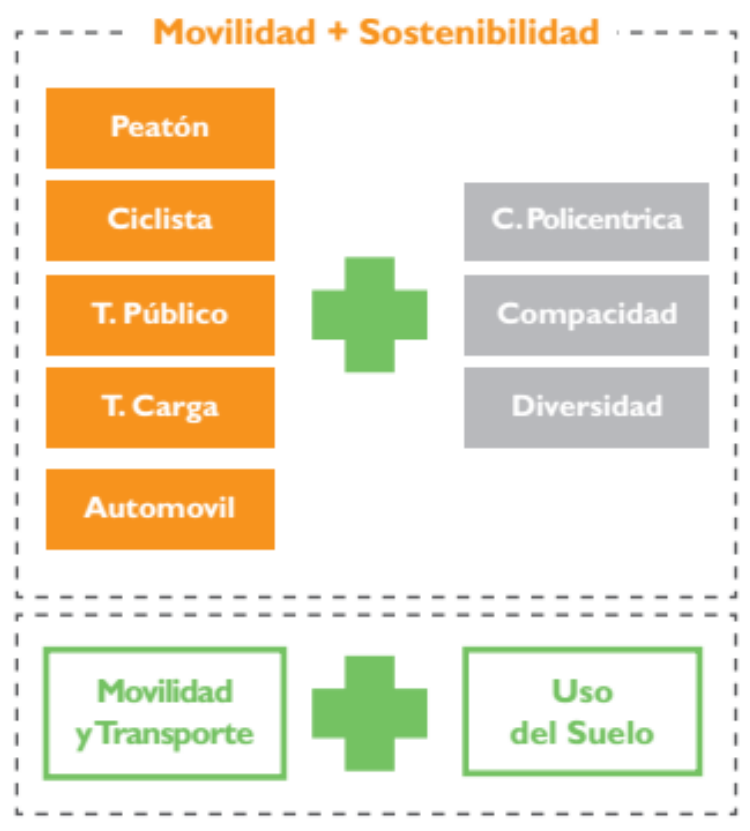

Gráfico 2. Gráfico que resume el vínculo entre la movilidad, el transporte y la planificación urbana. Fuente: Dextre y Avellaneda (2014) 


\section{b. Los Planes Directores en Arequipa: Problemas, visión de ciudad y el enfoque del sector transporte.}

En las últimas décadas, Arequipa ha experimentado un proceso parecido al de Lima metropolitana de los años 20 en los ejes de expansión urbana, crecimiento demográfico y económico. Como enuncia Fernández de Córdova y Vilela (2015), «la densificación de las actividades urbanas se produjo debido a ciertas intervenciones urbanas públicas y privadas que se localizan en toda la ciudad, guiadas por el criterio capitalista de mercado».

En la última década, el crecimiento en los tres ejes es producto de explotación del sector primario en el rubro minero. La expansión de la ciudad se ha traducido en un crecimiento desordenado por la presencia de las invasiones, en adición a la reducción de la campiña y la especulación inmobiliaria. Las definiciones de ciudad intermedia enunciadas por Canziani, Revesz \& Belaunde (2013), Vergara (2013) y Carrión (2013) calzan en la descripción de Arequipa por su condición de intermediación, su dependencia económica del agro y el sector primario y los elementos de transición demográfica, reforma del estado y la función relacional multiescalar.

La problemática que en la actualidad experimenta Arequipa está organizada en seis principales rubros: 


\begin{tabular}{|c|c|}
\hline Rubro & Problemas \\
\hline Vialidad y transporte & $\begin{array}{l}\text { - } \text { Déficit de corredores viales. } \\
\text { - Excesivo número de viajes al centro } \\
\text { histórico. } \\
\text { - Falta de desarrollo de polos de atracción en } \\
\text { periferia. } \\
\text { - Vías intrusivas hacia el centro histórico. } \\
\text { - Déficit del sistema de transporte } \\
\text { multimodal. }\end{array}$ \\
\hline $\begin{array}{c}\text { Crecimiento urbano desordenado y no } \\
\text { planificado }\end{array}$ & $\begin{array}{l}\text { - Ocupación ilegal e informal del suelo } \\
\text { eriazo y de las áreas agrícolas. } \\
\text { - Subutilización de áreas urbanas } \\
\text { planificadas para expansión urbana aún no } \\
\text { ocupadas. } \\
\text { Ocupación y consolidación residencial en } \\
\text { áreas de riesgo de desastre. }\end{array}$ \\
\hline $\begin{array}{c}\text { Centralismo y concentración de } \\
\text { actividades de intercambio en el área } \\
\text { central }\end{array}$ & $\begin{array}{l}\text { - Concentración de diversidad de actividades } \\
\text { en el centro de la ciudad (cercado y } \\
\text { distritos aledaños) } \\
\text { Existencia de distritos dormitorios sin } \\
\text { centralidades productoras de diversas } \\
\text { actividades. }\end{array}$ \\
\hline Baja densidad urbana & $\begin{array}{l}\text { - El crecimiento especulativo y no } \\
\text { planificado de la ciudad ocupa áreas } \\
\text { ociosas y supone un alto costo en } \\
\text { infraestructura vial y servicios para cubrir } \\
\text { la necesidad. } \\
\text { - Áreas previstas para crecimiento urbano } \\
\text { están desocupadas. }\end{array}$ \\
\hline Baja calidad ambiental & $\begin{array}{l}\text { - Escasas áreas metropolitanas destinadas a } \\
\text { la recreación y mejora de calidad ambiental } \\
\text { de la ciudad. } \\
\text { - Incremento agravado de la desertificación } \\
\text { de la ciudad. }\end{array}$ \\
\hline $\begin{array}{l}\text { Falta de institucionalidad que haga } \\
\text { cumplir la regulación sobre el uso de } \\
\text { suelo urbano y rural de la ciudad }\end{array}$ & $\begin{array}{l}\text { - Falta de regulación efectiva para evitar los } \\
\text { procesos de invasiones, malas } \\
\text { interpretaciones de normas, incremento de } \\
\text { la especulación del suelo, corrupción y } \\
\text { debilitamiento institucional. }\end{array}$ \\
\hline
\end{tabular}

Cuadro 3. Rubros y problemas en la ciudad de Arequipa. Elaboración propia en base al PDAM 2016-2025. 
En las ciudades, los niveles de gobernanza establecen políticas urbanas para la dirección y planificación de las mismas. Estas políticas se traducen en normas e instrumentos tangibles para la organización sistemática. Los planes directores implementados por el gobierno provincial de Arequipa son una suma de esfuerzos por una guía para la planificación de la ciudad.

La historia de Arequipa trasmite la experiencia de la realización de 3 planes directores en los últimos 35 años, los cuales han normado el crecimiento urbano y las inversiones en la ciudad. El primero de 1980 al 2002, el segundo de 2002 al 2015, y el tercero y último del 2016 al 2025. El primero y el segundo plan, según el Impla (Instituto Municipal de Planeamiento de Arequipa, 2016), tuvieron serios problemas para la implementación y fiscalización, ya que no consideraron un área específica que realizara esa labor.

Los problemas a los que conllevó la ausencia de esta área se tradujeron en procesos urbanos considerados informales. En el año 2008, en la gestión de Simón Balbuena, se diseña un proceso para la formulación del plan de desarrollo concertado para la provincia de Arequipa $^{2}$, sin embargo, no se llega a implementar. En el 2010, en la gestión de Alfredo Zegarra, se toma la decisión de corregir el crecimiento distorsionado de la ciudad y contrata a una consultora para realizar el diagnóstico de las condiciones de Arequipa ${ }^{3}$. En el 2014, por ordenanza municipal se crea el Instituto Municipal de Planeamiento (Impla) como un órgano descentralizado de la Municipalidad Provincial de Arequipa con un ejercicio autónomo dentro del marco de la ley. Este órgano se encarga de establecer lineamientos, estrategias y políticas a seguir para la planificación y adecuada gestión del suelo en Arequipa.

Los dos planes directores ${ }^{4}(2002$ y 2016) muestran visiones y modelos de ciudad marcadas por lineamientos guiados por el desarrollo sostenible:

\footnotetext{
2 Disponible en: http://www.muniarequipa.gob.pe/descargas/transparencia/pdc/pdc_2008_2021.pdf

${ }_{3}^{3}$ Disponible en: http://www.gr-arquitectos.com/dcc-menu/66-plan-de-desarrollo-metropolitano-de-arequipa-peru

4 En este primer documento de trabajo se ha considerado en analizar los dos últimos planes directores por cuestiones metodológicas y accesibilidad a la información. En un trabajo posterior se espera completar el análisis con la información del primer plan director.
} 


\begin{tabular}{|c|c|c|}
\hline & Plan director 2002-2015 & Plan director 2016-2025 \\
\hline Visión de ciudad & $\begin{array}{l}\text { - } \begin{array}{l}\text { Arequipa, patrimonio cultural de la } \\
\text { humanidad. }\end{array} \\
\text { - } \\
\text { - Arequipa ciudad sustentable. } \\
\begin{array}{l}\text { Arequipa ciudad descentralizada y } \\
\text { participativa. }\end{array} \\
\text { - Arequipa ciudad oasis. } \\
\end{array}$ & $\begin{array}{l}\text { - Arequipa ciudad oasis, patrimonio } \\
\text { cultural de la humanidad y líder } \\
\text { macroregional sur. } \\
\text { Arequipa ciudad sustentable, } \\
\text { competitiva, armonía con la campiña. } \\
\text { - Arequipa ciudad planificada y segura } \\
\text { ante el riesgo de desastres. }\end{array}$ \\
\hline Modelo de ciudad & $\begin{array}{l}\text { Compacta y policéntrica: } \\
\text { Se orientó a la consolidación del área } \\
\text { central, dos centralidades en el norte y } \\
\text { sur, y cinco unidades funcionales } \\
\text { articuladas por un sistema vial } \\
\text { longitudinal de norte a sur, un anillo vial } \\
\text { y una malla arterial complementaria. }\end{array}$ & $\begin{array}{l}\text { Compacta y policéntrica: } \\
\text { Se constituye por la desconcentración del } \\
\text { área central, la consolidación de dos } \\
\text { centros secundarios (norte y sur), y seis } \\
\text { centros terciarios articulados por } \\
\text { corredores principales, secundarios y } \\
\text { anillos de circunvalación. }\end{array}$ \\
\hline $\begin{array}{c}\text { Políticas urbanas } \\
\text { para la } \\
\text { configuración de } \\
\text { aglomeración. }\end{array}$ & 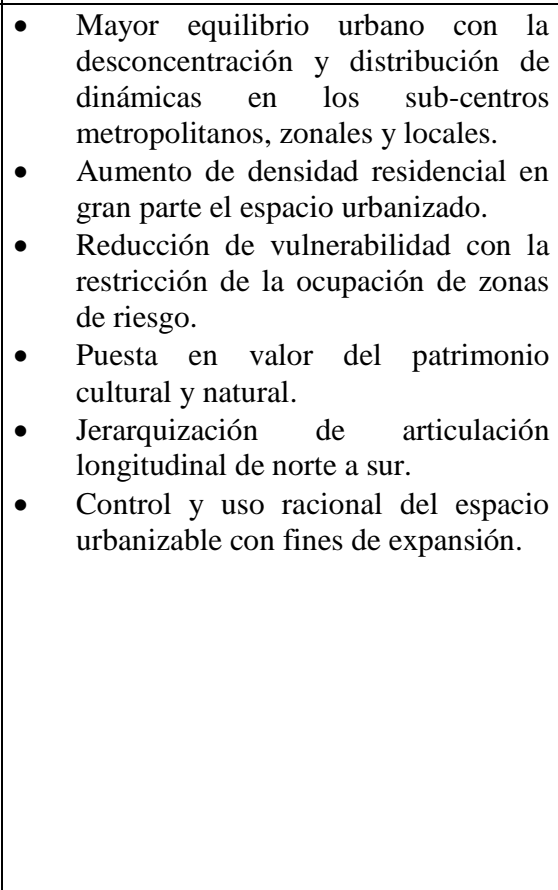 & 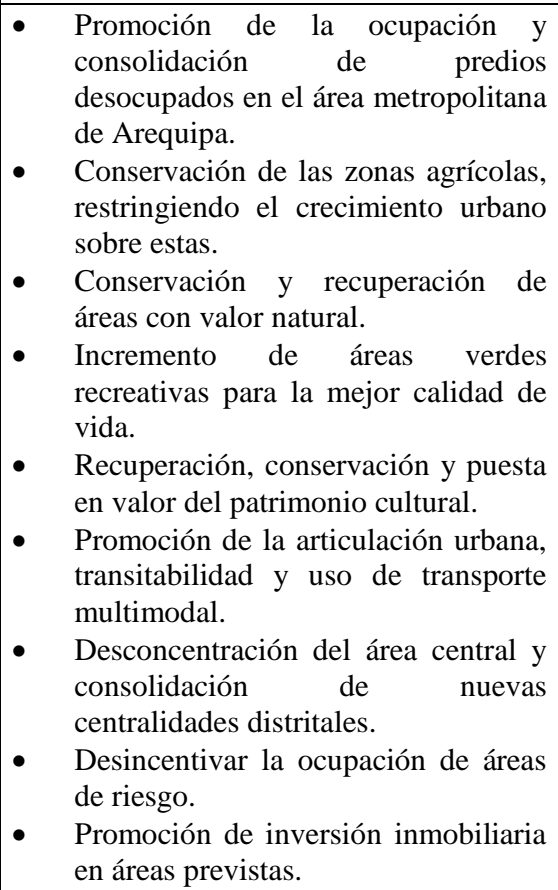 \\
\hline
\end{tabular}

Cuadro 4. Planes directores, visiones, modelos de ciudad y políticas para la configuración urbana. Elaboración propia en base al PDAM 2002-2015 y 2016-2025. 


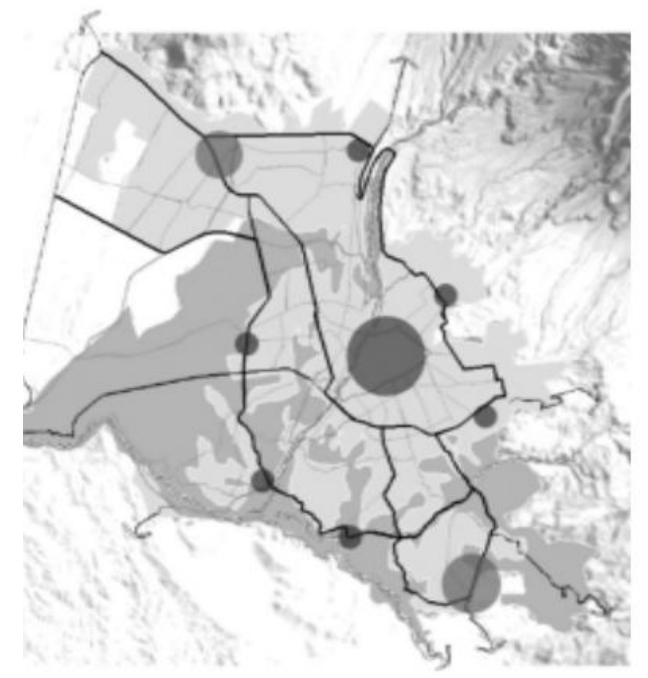

Imagen 6. Modelo de la ciudad de Arequipa 2002-2015

Fuente: http://www.labor.org.pe/descargas/cuaderno\%20de\%20debate\%204.pdf

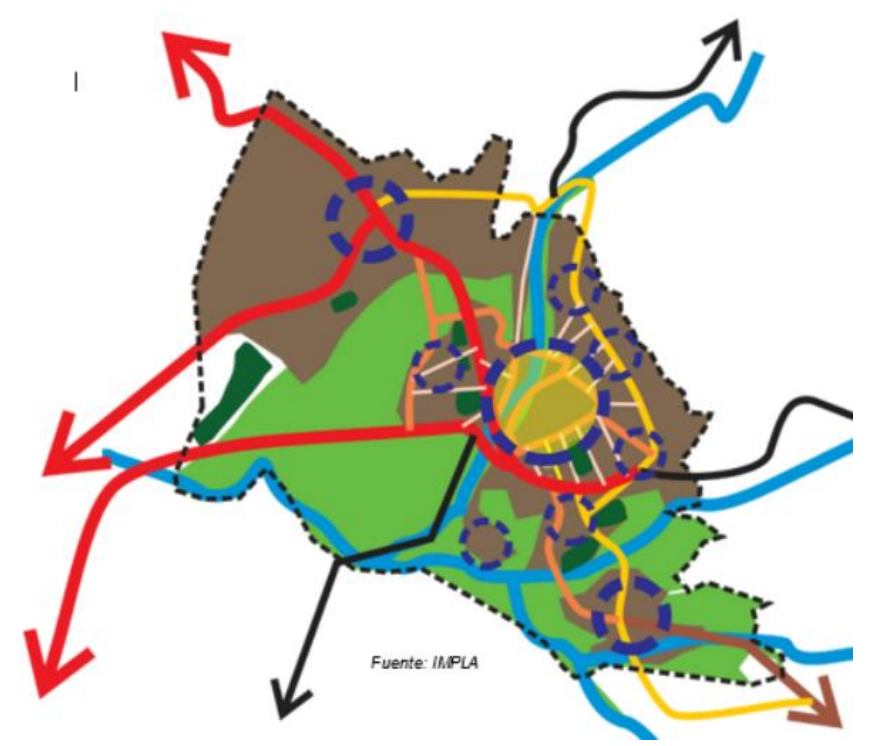

Imagen 7. Modelo de ciudad de Arequipa. 2016-2025

Fuente: http://impla.gob.pe/publicaciones/pdm-2016-2025/ 
La imagen 6 y la imagen 7 muestran gráficamente los modelos de ciudades que los planes directores evidencian. Ambos modelos expresan una voluntad de consolidación del área central y reforzar las centralidades distritales. Las diferencias varían en la cantidad de centralidades propuestas siendo en el PDM 2002 dos centralidades (norte y sur) y cinco unidades funcionales; en cambio en el PDM 2016 se configuran dos centralidades secundarias (norte y sur), y seis centralidades terciarias articuladas. Las centralidades están conformadas por equipamientos urbanos que brindan servicios de comercio, salud, educación, recreación y otros usos, para lo cual se ha catalogado en nivel local, zonal y metropolitano según el radio de influencia.

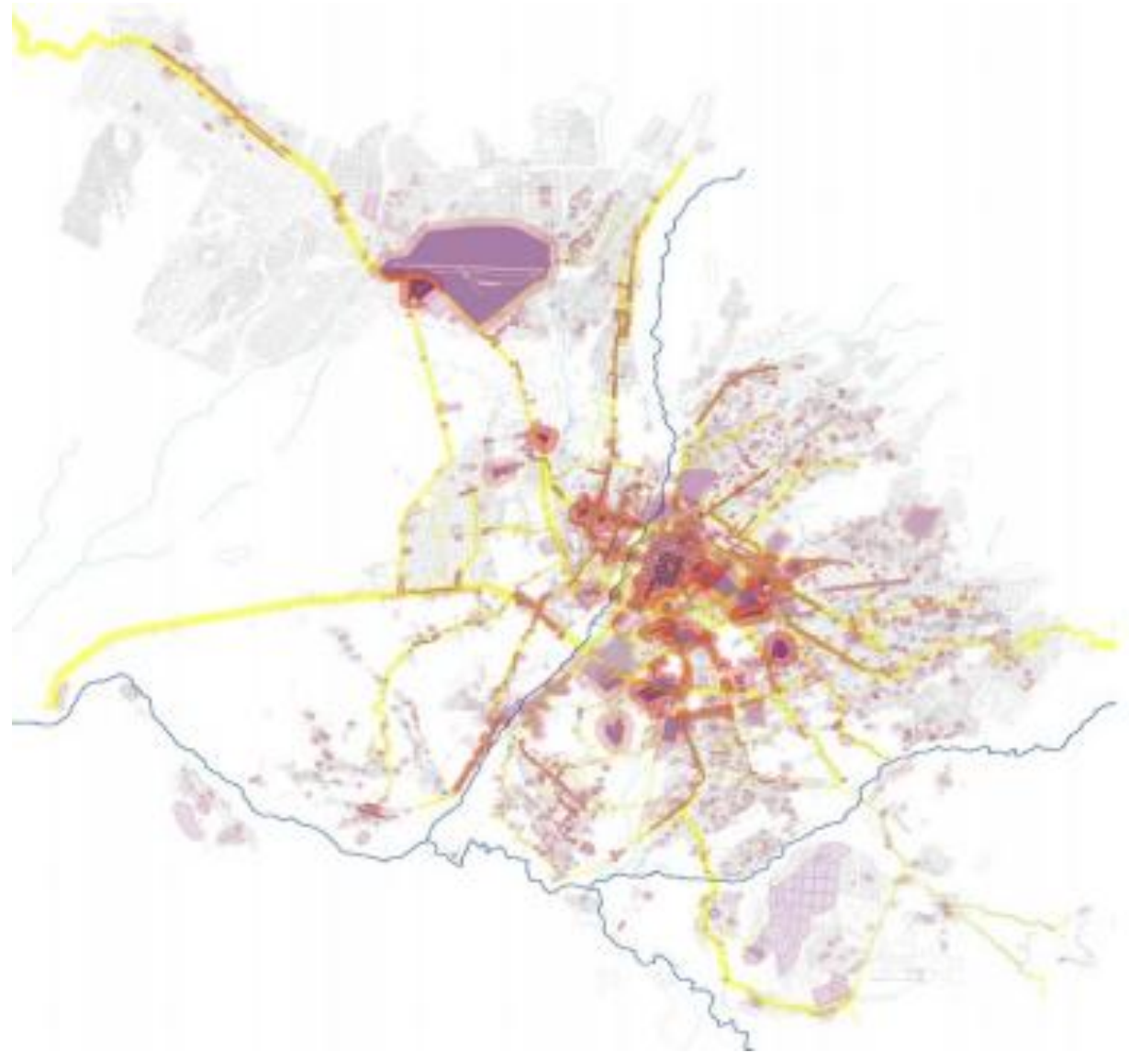

Imagen 8. Mapa de análisis de centralidades Arequipa Urbana 2015. Fuente:

http://impla.gob.pe/publicaciones/pdm-2016-2025/ 
En la imagen 8, las manchas violetas y rojas evidencian el carácter radiocéntrico de la ciudad de Arequipa y la falta de consolidación y aislamiento que tiene una centralidad en la zona norte. De igual manera, se observa que en varios distritos de la provincia existen equipamientos menores dispersos, lo cual induce a la codependencia de los distritos aledaños hacia el área central.

Luego de la revisión de la visión, modelos y políticas que establecen la configuración de la ciudad, las centralidades, definidas en los planes directores, se articulan por medio de un sistema vial para su integración. De esta manera, los sistemas viales para la articulación de la ciudad se describen como:

\begin{tabular}{|c|c|c|}
\hline & Plan director 2002-2015 & Plan director 2016-2025 \\
\hline Sistema vial & $\begin{array}{l}\text { Sistema vial estructurado por: } \\
\text { - } \text { Ejes longitudinales Principales } \\
\text { Eje Metropolitano } \\
\text { Vía lineal de } 24.14 \mathrm{~km} \text { de sección variable } \\
\text { entre 32.4m - 57.6m } \\
\text { Articula centralidad norte, principal y sur. } \\
\text { Contiene servicios especializados de } \\
\text { carácter regional y metropolitano. } \\
\text { Soporta el transporte masivo } \\
\text { metropolitano (BTR), transporte } \\
\text { particular a velocidad, sectores de tráfico } \\
\text { pesado y ferrocarril. } \\
\text { Eje Residencial } \\
\text { Vía lineal paralela al eje metropolitano de } \\
\text { 40.52km y de sección variable entre 21m } \\
\text {-90m. soporta el transporte masivo. } \\
\text { Eje agrícola } \\
\text { Vía lineal paralela al eje metropolitano de } \\
\text { 26.3km de norte a sur. Estructura áreas de } \\
\text { producción agrícola, forestación y } \\
\text { arborización, recreativas y paisajistas, } \\
\text { ciclovía. } \\
\text { Ejes secundarios } \\
\text { Eje Ecológico Metropolitano } \\
\text { Vía lineal transversal a la ciudad } \\
\text { configurado por el río chili. } \\
\text { Eje Blanco } \\
\text { Vía lineal transversal ubicado al norte de } \\
\text { la ciudad } \\
\text { Eje Azul } \\
\text { Vía lineal transversal ubicado en la zona } \\
\text { sur. } \\
\text { Ejes de integración }\end{array}$ & $\begin{array}{l}\text { - Sistema vial estructurado en red articulando } \\
\text { área metropolitana con las unidades urbanas. } \\
\text { Criterio de potenciación del transporte } \\
\text { público con carriles segregados } \\
\text { complementados por red de ciclovías y } \\
\text { zonas peatonalizadas. } \\
\text { Planteamiento de intercambiadores modales } \\
\text { en los distintos niveles de transporte de } \\
\text { pasajeros: } \quad \text { SIT } 4 \text { troncales, vías } \\
\text { - estructurantes y alimentadoras) } \\
\text { - Redes de autobuses provinciales y } \\
\text { regionales } \\
\text { Red de ciclovías } \\
\text { Línea tren de cercanías } \\
\text { Conexión aeroportuaria } \\
\text { Sistema vial estructurado por: } \\
\text { - } \\
\text { Vías interregionales } \\
\text { Carretera de integración de la } \\
\text { Costa } \\
\text { Variante de Uchumayo y } \\
\text { Panamericana. } \\
\text { Carretera de integración regional } \\
\text { de la Sierra } \\
\text { Carretera Yura, Av. Aviación y vía de } \\
\text { evitamiento. } \\
\text { Vías expresas } \\
\text { En Cerro Colorado } \\
\text { Av. Aviación, Av. Villa hermosa, } \\
\text { Autopista Arequipa- La joya. } \\
\text { En Yanahuara - Sachaca } \\
\text { Av. Paralela a vía de ferrocarril } \\
\text { En Arequipa }\end{array}$ \\
\hline
\end{tabular}




\begin{tabular}{|c|c|c|}
\hline & 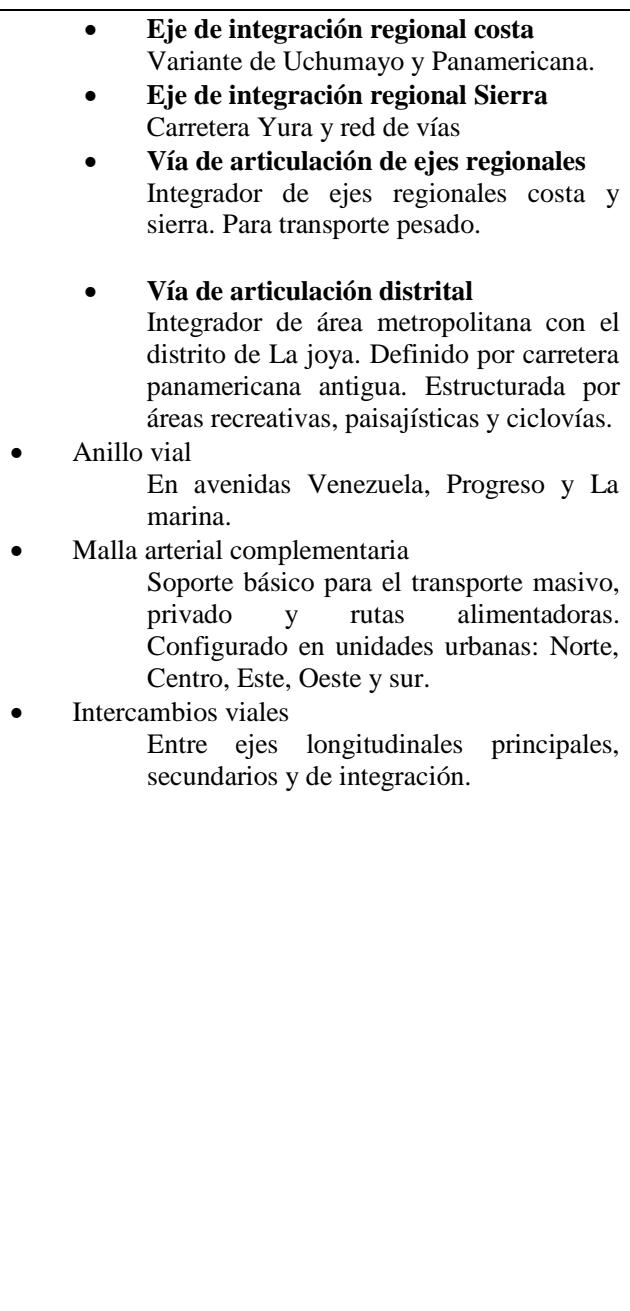 & 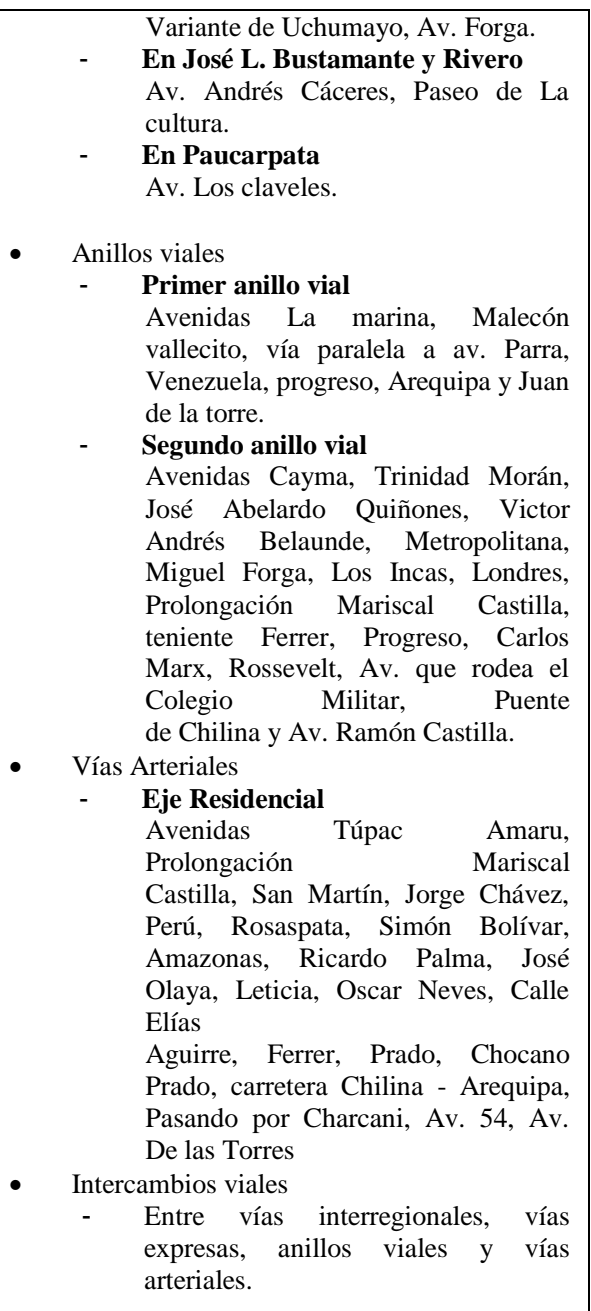 \\
\hline $\begin{array}{c}\text { Enfoque de } \\
\text { transporte } \\
\text { (basado en } \\
\text { Dextre y } \\
\text { Avellaneda) }\end{array}$ & Transporte público (1)- Tráfico (2) - movilidad (3) & $\begin{array}{l}\text { Transporte público (1) } \\
\text { - movilidad (2) - tráfico (3) }\end{array}$ \\
\hline
\end{tabular}

Cuadro 5. Planes directores, sistema vial y enfoque de transporte. Elaboración propia en base al PDAM 2002-2015 y 2016-2025. 
La revisión del sistema vial permite determinar complementariamente cuál ha sido el enfoque de transporte propuesto en el plan director. En ambos casos, el enfoque de transporte resultante es una combinación entre enfoques con diversas prioridades:

En el caso de la interpretación del PDM 2002 - 2015, existe una visión y modelo de ciudad guiados a un criterio de compacidad y policentralidad, lo cual se traduce en un enfoque de movilidad o movilidad sostenible. Sin embargo, al evaluar el eje de transporte, la solución proyecta ejes longitudinales principales y transversales guiados bajo criterio de tráfico (ensanche de la vía) y robustecimiento del transporte público. La ciudad aun es pensada bajo la sombra del auto y no del usuario. Es por ello que el criterio de prioridad en este plan director sería de (1) transporte público, (2) tráfico y (3) movilidad.

En el caso de la interpretación del PDM 2016 - 2025, de igual manera, existe una visión y modelo de ciudad guiados a un criterio de compacidad y policentralidad, además de complementarse con la diversidad de opciones para la movilización con la implementación de un sistema integrado de transporte: zonas peatonalizadas y creación de red de ciclovías dentro de un marco de robustecimiento del transporte público (uso de bus de transporte rápido, red de autobuses provinciales y regionales, tren de cercanías). Sin embargo, dentro del marco de la planificación existen obras de infraestructuras de gran capacidad (intercambios viales, vías expresas) que pueden generar complementariedad en el diseño de la ciudad.

Arequipa tiene como prioridad el ordenamiento del sistema de transporte público y su capacidad de transportar más pasajeros; paralelamente se realiza un esfuerzo por considerar el criterio de movilidad considerando al espacio público, la peatonalización y la red de ciclovías. Es por ello que el criterio de prioridad en este plan director sería de (1) transporte público, (2) movilidad y (3) tráfico. 


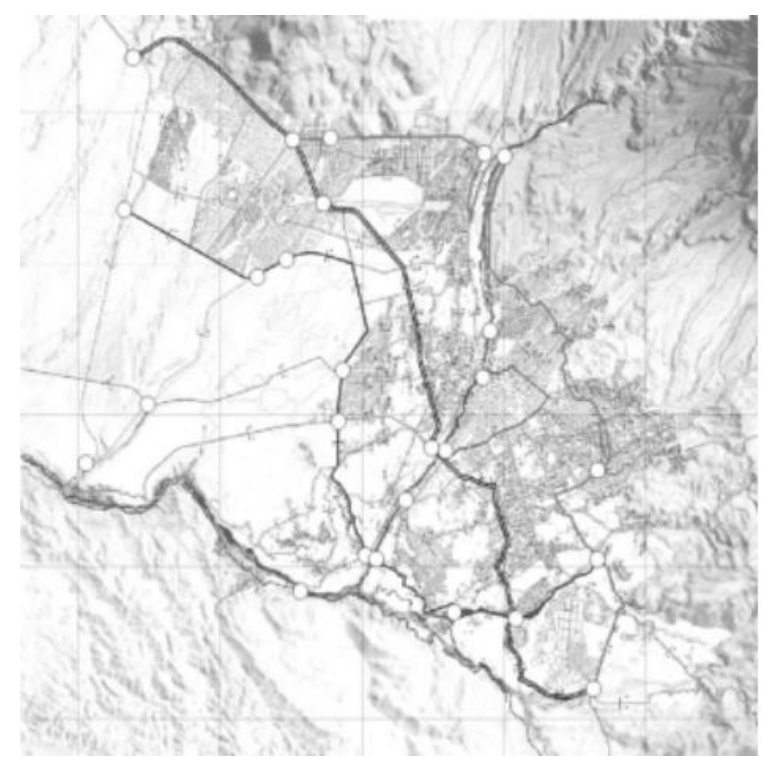

Imagen 9. Sistema vial de la ciudad de Arequipa 2002-2015.

Fuente: http://www.labor.org.pe/descargas/cuaderno\%20de\%20debate\%204.pdf

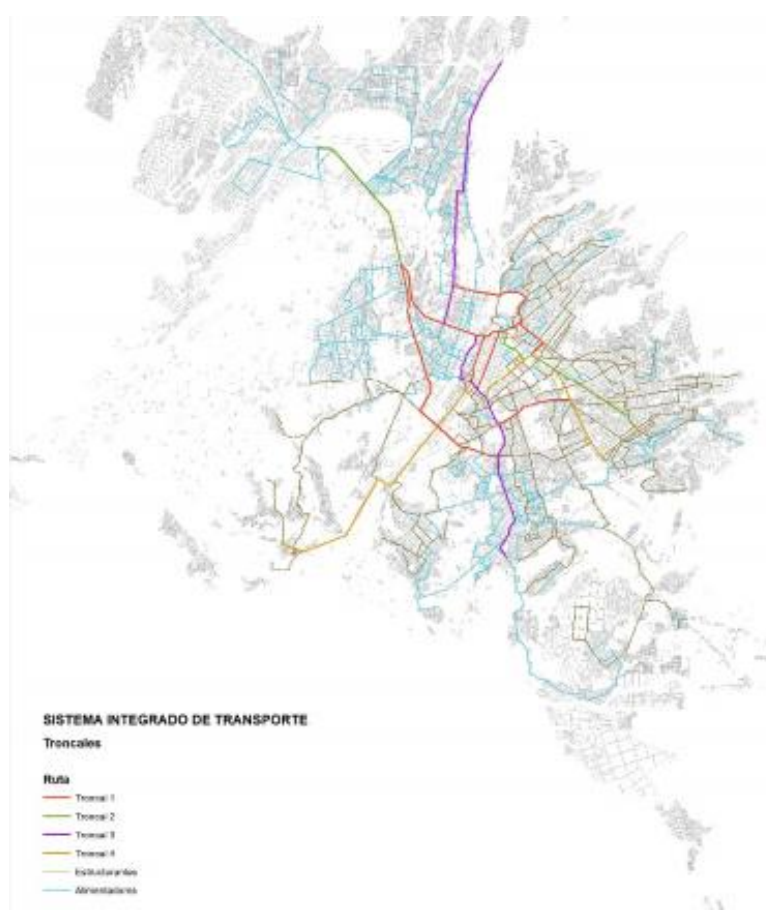

Imagen 10. Sistema vial de ciudad de Arequipa. 2016-2025. 
La imagen 9 y la imagen 10 muestran gráficamente el sistema vial propuesto en ambos planes directores. El plan director 2002-2015 describe una conexión longitudinal principal de norte a sur, dos longitudinales menores paralelas a la principal y tres conexiones transversales principales en el norte, centro y sur, además de un anillo vial y una malla arterial complementaria. En cambio, el plan director 2016-2025 considera un sistema integrado de transporte comprendido por 4 rutas troncales, vías estructurantes y vías alimentadoras. Adicionalmente, este sistema está dentro de una estructura vial compuesta por vías interregionales, vías expresas, dos anillos viales y vías arteriales.

La imagen 11 presenta el mapa de análisis de la red vial de Arequipa, el cual muestra el estudio del nivel de integración de la red vial según su topografía y geometría. Este análisis realizado por la consultora GR Arquitectos Perú permitió comprender la integración y preferencia de las vías actuales.

Imagen 11. Mapa de análisis de la red vial de Arequipa Urbana 2015.

Fuente: http://impla.gob.pe/publicaciones/pdm-2016-2025/ 


\section{La inversión pública y los instrumentos de planificación}

\section{a. Aproximación metodológica propuesta para identificar los enfoques de transporte en los proyectos de inversión pública en los planes directores.}

La definición de inversión pública según el Ministerio de Economía y Finanzas $^{5}$ está directamente relacionada al gasto o «gasto de capital» que genera el sector público (en este caso, el gobierno local) para la realización de Proyectos de Inversión Pública (PIP) ${ }^{6}$. «La inversión pública es el dinero utilizado principalmente para la ejecución de obras físicas que pueden ser consideradas como bienes de capital del Estado» (Espinoza \& Fort, 2017).

En ese sentido, la inversión pública está directamente ligada a los instrumentos de planificación debido a que los planes directores contienen los lineamientos para la realización de proyectos de inversión pública como obras y proyectos vinculados al rubro de transporte. Además, los gobiernos locales tienen una estructura definida para el manejo de un presupuesto disponible para la ejecución de obras y proyectos que respondan a un marco de planificación. La herramienta para el análisis de los gastos realizados por la municipalidad provincial de Arequipa ha sido la data mostrada por el portal de transparencia económica ${ }^{7}$ del Ministerio de Economía y Finanzas que consulta el seguimiento de la ejecución de proyectos de inversión pública.

Con la búsqueda de la data, se clasifican los proyectos de inversión de la municipalidad provincial de Arequipa realizados en el eje o rubro de transporte en los años disponibles de la base de datos ${ }^{8}$. Esta información se

\footnotetext{
5 Disponible en: https://www.mef.gob.pe/es/glosario-de-inversion-publica

${ }^{6}$ Definido según el MEF como "Toda intervención limitada en el tiempo que utiliza total o parcialmente recursos públicos, con el fin de crear, ampliar, mejorar, modernizar o recuperar la capacidad productora de bienes 0 servicios; cuyos beneficios se generen durante la vida útil del proyecto y éstos sean independientes de los de otros proyectos".

${ }^{7}$ Disponible en: http://apps5.mineco.gob.pe/bingos/seguimiento_pi/Navegador/default.aspx

8 Para fines de este estudio se consideró la información disponible en la base de datos correspondiente a los años 2014, 2015, 2016 y 2017. Sin embargo, existen dentro de la base de datos proyectos de inversión que datan de los años 2007 y aún se encuentran en ejecución. Otros proyectos se reconocen como no activos debido al cambio de plataforma SNIP por la actual gestión del gobierno central que se consideraran como proyectos de la actual gestión municipal provincial de Arequipa. Para la realización de los cuadros comparativos entre planes directores y años (cuadro 5 al 8) se optó por hacer una comparación entre los dos siguientes años de iniciada una gestión municipal (2011 y 2015) para hallar proporcionalidad y equivalencia.
} 
clasifica por proyectos, gestiones municipales, fechas de viabilidad, Estado, costo, ejecución a los años, ejecución total y porcentaje de avance.

El cuadro 6 describe el gasto en el rubro transporte como un gasto importante en el presupuesto de la gestión, ya que no disminuye del treinta por ciento del presupuesto general. Sin embargo, en el gasto total y el gasto en el rubro de transporte se considera todo tipo de obras que no necesariamente están aprobadas, en ejecución o tienen código SNIP.

\begin{tabular}{|c|c|c|c|c|}
\hline Plan director & Año & $\begin{array}{c}\text { Gasto total } \\
\text { (Nuevos soles) }\end{array}$ & $\begin{array}{c}\text { Gasto rubro } \\
\text { transporte } \\
\text { (nuevos } \\
\text { soles) }\end{array}$ & $\begin{array}{c}\text { Gasto rubro } \\
\text { transporte } \\
\text { (porcentaje) }\end{array}$ \\
\hline $2002-2015$ & 2012 & 780167879 & 239920223 & $30.75 \%$ \\
\cline { 2 - 5 } & 2013 & 686408578 & 275889505 & $40.19 \%$ \\
\hline $2016-2025$ & 2016 & 1768872116 & 647461381 & $36.60 \%$ \\
& 2017 & 668737090 & 233609691 & $34.93 \%$ \\
\hline
\end{tabular}

Cuadro 6. Plan director, año, gasto total, gasto en el rubro transporte en nuevos soles y porcentaje. Elaboración propia basada en la información del portal de transparencia económica del MEF. 
El cuadro 7 verifica cuanto ha sido el gasto anual en el rubro de transporte en obras que están aprobadas, en ejecución y con código SNIP 9 .

\begin{tabular}{|c|c|c|}
\hline Plan director & Año & $\begin{array}{c}\text { Gasto Total } \\
\text { (Rubro transporte) }\end{array}$ \\
\hline $2002-2015$ & 2012 & 7478809 \\
\cline { 2 - 3 } & 2013 & 81960769 \\
\hline $2016-2025$ & 2016 & 2684962 \\
\cline { 2 - 3 } & $2017^{10}$ & 686403 \\
\hline
\end{tabular}

Cuadro 7. Plan director, año y gasto total en nuevos soles en obras y proyectos en el rubro del transporte. Elaboración propia basada en la información del portal de transparencia económica del MEF.

Sin embargo, en el año 2013, se observa que existe una diferencia de gasto alta en comparación con el año anterior. Esto se debe al número de obras y proyectos en ejecución, el cual es mayor a los otros años.

\begin{tabular}{|c|c|c|}
\hline Plan director & Año & Número de Obras \\
\hline \multirow{2}{*}{$2002-2015$} & 2012 & 4 \\
\cline { 2 - 3 } & 2013 & 13 \\
\hline \multirow{2}{*}{$2016-2025$} & 2016 & 4 \\
\cline { 2 - 3 } & 2017 & 1 \\
\hline
\end{tabular}

Cuadro 8. Plan director, año y número de obras y proyectos en el rubro del transporte. Elaboración propia basada en la información del portal de transparencia económica del MEF.

En el año 2013 se ejecutan nueve obras más que en el 2012 y 2016, y doce obras más que en el 2017. A simple observación puede parecer un indicador de eficiencia de la gestión municipal. No obstante, en el cuadro 9 se agrega otra condicionante a la evaluación de las obras y proyectos: clasificación de

\footnotetext{
${ }^{9}$ Las obras y proyectos que cuentan con código SNIP son las de los años 2012 y 2013. Las del 2016 y 2017 no cuentan con código SNIP debido al cambio del sistema de inversión pública, sin embargo, se encuentran en ejecución.

10 Se considera el año 2017 dentro del estudio debido a la importancia de saber cual está siendo el enfoque de transporte que rige las obras ejecutadas como prioridad en la primera parte del año. No se considera al año 2015 dentro del estudio, ya que no se realizó ninguna obra y el plan director 2016-2015 recién entraba en vigencia.
} 
los tipos de obras según los enfoques de Dextre y Avellaneda en el sector del transporte.

\begin{tabular}{|c|c|c|c|c|c|}
\hline \multicolumn{2}{|c|}{ Plan director } & \multicolumn{2}{c|}{$\mathbf{2 0 0 2 - 2 0 1 5}$} & \multicolumn{2}{c|}{$\mathbf{2 0 1 6 - 2 0 2 5}$} \\
\hline \multicolumn{2}{|c|}{ Año } & $\mathbf{2 0 1 2}$ & $\mathbf{2 0 1 3}$ & $\mathbf{2 0 1 6}$ & $\mathbf{2 0 1 7}$ \\
\hline \multirow{2}{*}{$\begin{array}{c}\text { Tipos de } \\
\text { Obras } \\
\text { según los } \\
\text { enfoques } \\
\text { de Dextre } \\
\begin{array}{c}y \\
\text { Avellaneda }\end{array}\end{array}$} & $\begin{array}{c}\text { Tráfico } \\
\text { público }\end{array}$ & 3 & 9 & 1 & 0 \\
\cline { 2 - 6 } & Movilidad & 1 & 0 & 0 & 0 \\
\cline { 2 - 6 } & Sovilidad & 0 & 0 & 0 & 0 \\
\hline \multicolumn{2}{|c|}{ Número de Obras } & $\mathbf{4}$ & $\mathbf{1 3}$ & $\mathbf{4}$ & $\mathbf{1}$ \\
\hline
\end{tabular}

Cuadro 9. Plan director, año, tipos de obras y número de obras y proyectos en el rubro del transporte. Elaboración propia basada en la información del portal de transparencia económica del MEF.

Los cuatro enfoques cruzados con la información de los cuadros anterior detallan lo siguiente:

En el caso del 2012 y 2013, la mayor parte de las obras y proyectos realizados responden a un enfoque de tráfico. Los proyectos que responden a un enfoque de tráfico en estos años se describen como «Mejoramiento de la transitabilidad vehicular», «Mejoramiento vial», «Rehabilitación postdesastre del servicio de transitabilidad vehicular» y «construcción de intercambios viales». En cambio, los proyectos que responden a un enfoque de movilidad se describen solo como «Mejoramiento de la transitabilidad vehicular y peatonal».

En el caso de los años 2016 y 2017, la mayor parte de las obras corresponden al enfoque de movilidad, las cuales se describen como «Mejoramiento del cruce peatonal», «Mejoramiento de la transitabilidad peatonal», «mejoramiento de la transitabilidad vehicular y peatonal» $\mathrm{y}$ «Mejoramiento de la transitabilidad peatonal de la alameda». 


\begin{tabular}{|c|c|c|c|c|c|}
\hline \multirow{2}{*}{\multicolumn{2}{|c|}{$\frac{\text { Plan director }}{\text { Año }}$}} & \multicolumn{2}{|c|}{ 2002-2015 } & \multicolumn{2}{|c|}{ 2016-2025 } \\
\hline & & 2012 & 2013 & 2016 & 2017 \\
\hline \multirow{4}{*}{$\begin{array}{c}\text { Tipos de } \\
\text { Obras } \\
\text { según los } \\
\text { enfoques } \\
\text { de Dextre } \\
y \\
\text { Avellaneda }\end{array}$} & Tráfico & $75 \%$ & $69.2 \%$ & $25 \%$ & 0 \\
\hline & $\begin{array}{l}\text { Transporte } \\
\text { público }\end{array}$ & - & - & - & - \\
\hline & Movilidad & $25 \%$ & $30.8 \%$ & $75 \%$ & $100 \%$ \\
\hline & $\begin{array}{l}\text { Movilidad } \\
\text { Sostenible }\end{array}$ & - & - & - & - \\
\hline
\end{tabular}

Cuadro 10. Plan director, año, tipos de proyectos en el rubro del transporte en porcentajes. Elaboración propia basada en la información del portal de transparencia económica del MEF.

A pesar de ello, el número de obras realizadas en el 2012 y 2013 es mayor en comparación a las obras realizadas en el 2016 y 2017.

En consecuencia, se considera convertir las cifras en porcentajes para aplicar proporcionalidad entre ambas. En el cuadro 10 se observa con detalle la conversión del número de proyectos a porcentajes. El número de obras convertidas a porcentajes corroboran la prioridad de las obras en el rubro de transporte en las gestiones municipales ${ }^{11}$ en estos años: en el 2012 y 2013 la prioridad es el enfoque de tráfico; en el 2016 y 2017 la prioridad es el enfoque de la movilidad. De esta manera, la data sobre la prioridad de gasto de inversión pública según el enfoque que se tiene en el sector transporte se ve contrarrestada y expuesta con la información con los criterios de prioridad de los planes directores en el caso de los años 2012 y 2013.

Finalmente, esto permite intuir que los proyectos realizados en la ciudad pueden o no estar relacionados con el discurso vertido en el instrumento de planificación. En el caso del 2016 y 2017, posiblemente la condición de tener

\footnotetext{
${ }^{11}$ Es importante mencionar que las gestiones municipales del 2011 y 2015 son dirigidas por el mismo gobernante local: Alfredo Tejada Zegarra.
} 
un organismo de planificación como el Impla permite regular la ejecución de proyectos en determinados plazos.

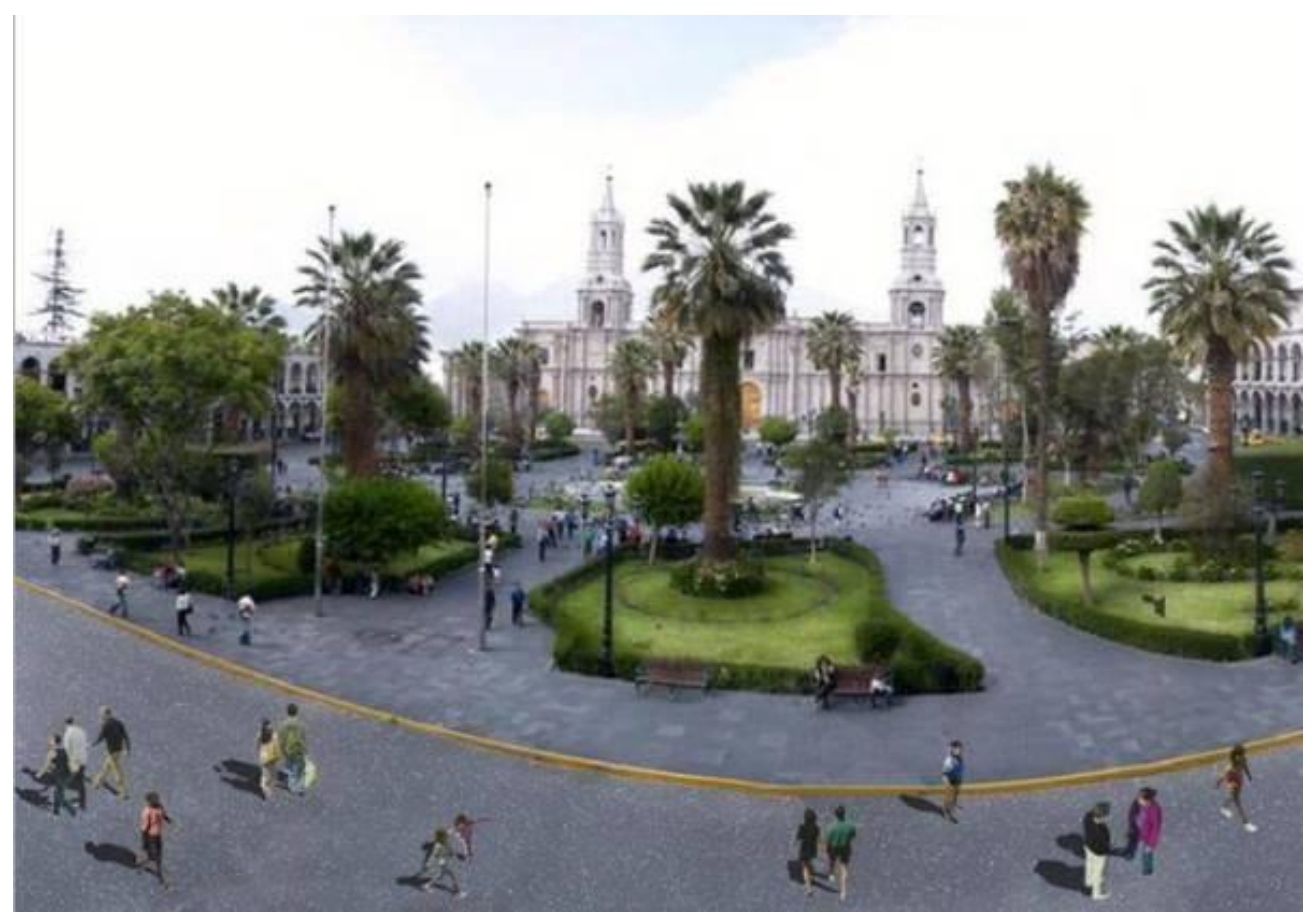

Imagen 12. Mejoramiento de la transitabilidad peatonal en la plaza mayor de Arequipa y calles adyacentes.

Fuente: http://prensatur.pe/2015/06/arequipa-ensaya-la-peatonalizacion-de-su-plaza-de$\underline{\operatorname{armas}}$ 


\section{Conclusiones}

1. Los planes directores son un instrumento de planificación que puede cumplir la función de regulación al establecer un horizonte en la realización de Proyectos de Inversión Pública.

2. La visión de ciudad, el modelo de ciudad y los proyectos a realizar en el sector transporte (que corresponden a los planes directores) están directamente relacionados, son parte de un sistema integral y son resultados de políticas urbanas.

3. Arequipa es una ciudad dispersa con una estructura concéntrica (en la práctica) y busca ser una ciudad compacta y policéntrica (en teoría).

4. Las visiones y modelos de ciudad de ambos planes directores en Arequipa (2002 y 2015) son similares; no obstante, las estrategias y los proyectos a realizar por las gestiones municipales, en los años 2012, 2013, 2016 y 2017 para llegar a aquellas visiones de ciudades, son distintos y tienen enfoques de tráfico y movilidad respectivamente.

5. Los enfoques de transporte son herramientas conceptuales importantes que devienen en políticas urbanas y se materializan en los planes directores.

6. Establecer la relación entre proyectos a realizarse según planificación y proyectos registrados en las bases de datos del Estado permite ser un instrumento de fiscalización para detectar el grado o nivel de eficiencia en la realización de obras de inversión pública por temporalidades para la evaluación de los gobiernos locales. 


\section{Bibliografía}

Asociación civil LABOR (2008). Ciudad Oasis. Cuaderno de debate 4.

Disponible

en

http://www.labor.org.pe/descargas/cuaderno\%20de\%20debate\%204.p $\underline{\mathrm{df}}$

Avellaneda, P. (2008). Ciudad popular, organización funcional y movilidad. Reflexiones sobre Lima Metropolitana. Revista Cuadernos: Arquitectura y ciudad, 6, 1-125.

Bellet, C. y Llop, J. (2004). Miradas a otros espacios urbanos: las ciudades intermedias. Disponible en http://www.ub.edu/geocrit/sn/sn-165.htm

Bensús, V. y Pérez, A. (2014). Nuevas dinámicas territoriales en ciudades intermedias. El caso de Huamachuco, La libertad. Revista Cuadernos: Arquitectura y ciudad, 20, 1-73.

Beuf, A. (2010). Nuevas centralidades y acceso a la ciudad en las periferias bogotanas. Boletín del Instituto francés de estudios andinos, 40, 147178.

Buchanan, C. (1973). El tráfico en las ciudades. Madrid: Tecnos.

Canziani, J., Revesz, B. y Belaunde, P. (2013). Piura: ciudades intermedias y desarrollo territorial. En J, Canziani y A, Schejtman (Eds.), Ciudades intermedias y desarrollo territorial. (pp. 109-137). Lima: PUCP

Canziani, J. y Schejtman, A. (2013). Ciudades Intermedias y desarrollo territorial. Lima: Fondo Editorial PUCP. 
Carrión, F. (2013). Ciudades intermedias: entre una pirámide trunca y una red urbana en construcción. En J, Canziani y A, Schejtman (Eds.), Ciudades intermedias y desarrollo territorial. (pp. 21-31). Lima: PUCP.

Castañer, M. y Gutiérrez, O. (2006). Movilidad y estructuración de áreas urbanas. El caso de dos ciudades intermedias: Olot y Figueres. Disponible en http://www.cervantesvirtual.com/obra/movilidad-yestructuracin-de-reas-urbanas-el-caso-de-dos-ciudades-intermediasolot--y-figueres-0/

Cebollada, A. (2007). Aproximación a los procesos de exclusión social a partir de la relación entre el territorio y la movilidad cotidiana. Documents d'Analisi Geográfica, 48, 105-121

Dextre, J. y Avellaneda, P. (2014). Movilidad en zonas urbanas. Lima: Fondo Editorial PUCP.

Espinoza, A. y Fort, R. (2017). Inversión sin planificación: La calidad de la inversión pública en los barrios vulnerables de Lima. Lima: GRADE.

Fernández de Córdova, G. y Vilela, M. (2015). Reflexiones sobre densidad urbana y centralidades en la metrópoli de Lima, siglo XXI. Revista Ensayo, 1, 83-114.

GR arquitectos Perú S.A.C. y García de los Reyes Arquitectos Asociados S.A.C. (2012). Evaluación de estudios e instrumentos de gestión. Disponible en http://www.gr-arquitectos.com/dcc-menu/66-plan-dedesarrollo-metropolitano-de-arequipa-peru 
Instituto Municipal de Planeamiento de Arequipa (2016). Plan de Desarrollo de Arequipa. Disponible en http://impla.gob.pe/publicaciones/pdm$\underline{2016-2025 /}$

López, F., Nieto, D. y Arias, C. (2010) Relaciones entre el concepto de movilidad y la ocupación territorial de Medellín. Revista EIA, 13, 2337.

Municipalidad Provincial de Arequipa (2002). Plan Estratégico de Arequipa Metropolitana (PEAM). Disponible en https://es.scribd.com/document/42975247/Plan-Estrategico-deArequipa

Municipalidad Provincial de Arequipa (2007). Adecuación del Plan Director de Arequipa Metropolitana 2002-2015 al Reglamento de Acondicionamiento Territorial y Desarrollo Urbano. Disponible en https://es.scribd.com/doc/91620617/324-Adecuacion-Pdam-Final

Municipalidad Provincial de Arequipa (2008). Proceso de reformulación del Plan de Desarrollo Concertado de la Provincia de Arequipa 2008-2021. Disponible en http://www.muniarequipa.gob.pe/descargas/transparencia/pdc/pdc_200 8_2021.pdf

Novas, M. (2014). Arquitectura y género. Una reflexión teórica. Disponible en http://www.dexeneroconstrucion.com/mnovas_arquitecturaygenero.pdf 
Oliva, J. (2005). La confusión del urbanismo: ciudad pública vs ciudad doméstica. Disponible en http://www.ub.edu/geocrit/b3w-628.htm

Rueda, S. (1997). La ciudad compacta y diversa frente a la conurbación difusa. Disponible en http://habitat.aq.upm.es/cs/p2/a009.html

Rueda, S. (2002). El urbanismo ecológico. Disponible en http://urbane.aq.upm.es/articulos/ver/el-urbanismo-ecol-gico/completo

Sánchez, V. (2013). Policentrismo morfológico y funcional. Una perspectiva mexicana.

Disponible

en http://www.uab.cat/web/doctorat/servlet/BlobServer?blobtable=Docum ent\&blobcol=urldocument\&blobheader=application/pdf\&blobkey=id\& blobwhere $=1345657403859 \&$ blobnocache $=$ true

Sanz, A. (1997). Movilidad y accesibilidad: un escollo para la sostenibilidad urbana. Documento de ciudades para un futuro más sostenible. Disponible en http://habitat.aq.upm.es/cs/p3/a013.html

Sanz, A. (2008). Calmar el tráfico. Pasos para una nueva cultura de la movilidad urbana. Madrid: Gobierno de España, Ministerio de Fomento

Tonucci, F. (2004). La ciudad de los niños. Un nuevo modo de pensar la ciudad. (tercera edición). Buenos Aires: Losada.

Tyler, N. (2002). Accesibility and the Bus System. From Concepts to Practice. Londres: Thomas Telford. 
Vega Centeno, P. (2003). Movilidad (espacial) y vida cotidiana en contextos de metropolización. Reflexiones para comprender el fenómeno urbano contemporáneo. Revista Debates en Sociología, 28, 19-51.

Vega Centeno, P. (2004). Movilidad y vida cotidiana de mujeres de sector popular de Lima. Un análisis del testimonio de la señora Eufemia. Revista Anthropologica, 22, 31-62.

Vega Centeno, P. (2006). El espacio público: La movilidad y la revaloración de la ciudad. Revista Cuadernos de Arquitectura y ciudad, 3, 1-75.

Vergara, R. (2013). Ciudades rurales y superación de la pobreza extrema. En J, Canziani y A, Schejtman (Eds.), Ciudades intermedias y desarrollo territorial. (pp. 61-70). Lima: PUCP. 